
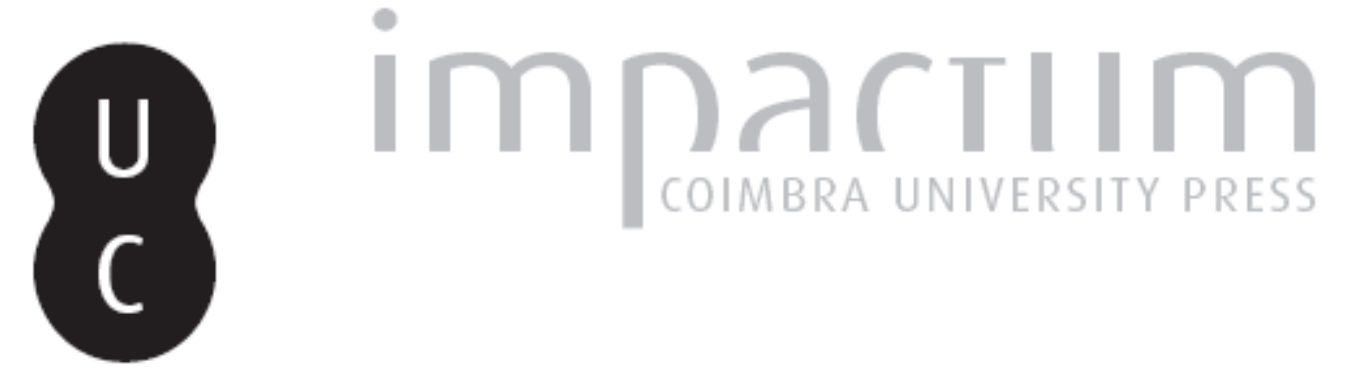

\title{
Os hebdomadários de Severino Boécio
}
Autor(es): $\quad$ Silveira, Carlos Frederico Gurgel Calvet da
Publicado por: Universidade Católica de Petrópolis; Instituto Brasileiro de Informação em Ciência e Tecnologia

URL

persistente:

URI:http://hdl.handle.net/10316.2/33060

DOI:

DOI:http://dx.doi.org/10.14195/1984-6754_3-1_7

Accessed : $\quad$ 26-Apr-2023 05:01:10

A navegação consulta e descarregamento dos títulos inseridos nas Bibliotecas Digitais UC Digitalis, UC Pombalina e UC Impactum, pressupõem a aceitação plena e sem reservas dos Termos e Condições de Uso destas Bibliotecas Digitais, disponíveis em https://digitalis.uc.pt/pt-pt/termos.

Conforme exposto nos referidos Termos e Condições de Uso, o descarregamento de títulos de acesso restrito requer uma licença válida de autorização devendo o utilizador aceder ao(s) documento(s) a partir de um endereço de IP da instituição detentora da supramencionada licença.

Ao utilizador é apenas permitido o descarregamento para uso pessoal, pelo que o emprego do(s) título(s) descarregado(s) para outro fim, designadamente comercial, carece de autorização do respetivo autor ou editor da obra.

Na medida em que todas as obras da UC Digitalis se encontram protegidas pelo Código do Direito de Autor e Direitos Conexos e demais legislação aplicável, toda a cópia, parcial ou total, deste documento, nos casos em que é legalmente admitida, deverá conter ou fazer-se acompanhar por este aviso.

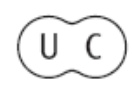



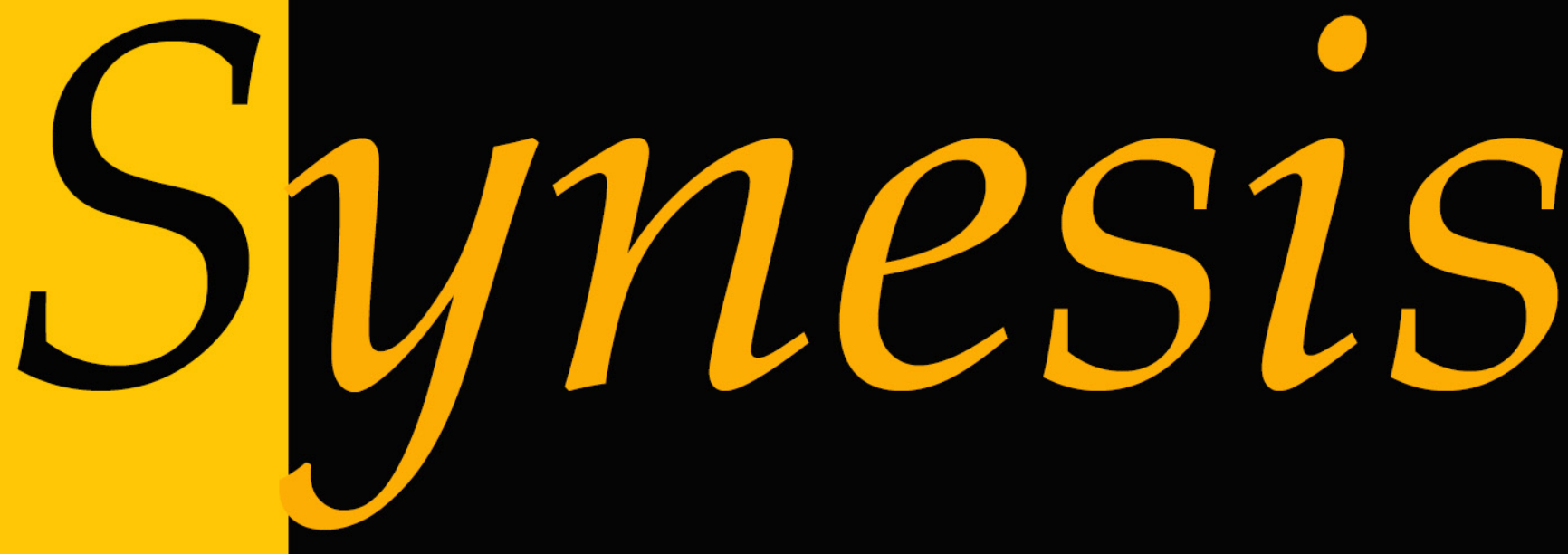

Revista do Centro de Teologia e Humanidades ISSN 1984-6754

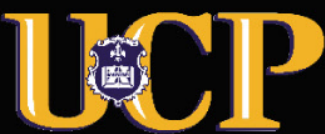




\title{
Os Hebdomadários de Severino Boécio ${ }^{1}$
}

\author{
Tradução, introdução e notas de \\ Carlos Frederico Gurgel Calvet da Silveira ${ }^{2}$
}

\section{Introdução aos Hebdomadários}

Este importante texto de Boécio tem claramente cinco partes: 1) o proêmio, no qual se apresentam o tema e o método a ser seguido a um suposto diácono de nome João; 2) um conjunto de sete princípios, que serão a base da argumentação do autor; 3) a questão a ser resolvida; 4) a solução; 5) finalmente, a resposta a duas objeçóes para arrematar a argumentação.

As opções de tradução devem ser justificadas em alguns casos importantes. O termo substantia foi traduzido tanto por substância como por essência, pois os dois sentidos se encontram em Boécio, ou seja, o sentido de substância primeira e o de substância segunda, respectivamente. Já o adjetivo substantialis foi traduzido literalmente por estar claro nas passagens em que aparece.

A tradução que se segue tem por objetivo tornar disponível em português, especialmente para os estudantes de Metafísica e de Medieval, mais uma versão do famoso texto de Boécio. Remete-se aqui, conforme se pode ver na referência bibliográfica, ao imponente trabalho do Prof. Juvenal, que não somente oferece aos leitores uma boa traduçáo desse texto, com o orginal ao lado, mas sobretudo pelo excelente estudo sobre a obra de Boécio.

\footnotetext{
${ }^{1}$ Tradução recebida em 06/08/10 e aprovado para publicação em 08/10/10.

2 Doutor em Filosofia pela Pontificia Università San Tommaso (Roma). Professor Adjunto da Universidade Católica de Petrópolis. Currículo Lattes: http://lattes.cnpq.br/4874832664252533. E-mail: carlos.silveira@ucp.br.
} 


\section{Os Hebdomadários}

De que modo as substâncias, na medida em que são, são boas mesmo não sendo boas por essência

Pedes que eu esclareça e exponha paulatinamente e com mais clareza a obscura questáo dos nossos Hebdomadários que versa sobre o modo pelo qual as substâncias sáo boas enquanto são, embora não sejam bens substanciais. E dizes que isso deve ser feito porque o método desse tipo de escrito náo é conhecido por todos. Eu mesmo sou tua testemunha de que, com vivacidade, abraçaste esta questáo. Eu comento para mim mesmo os Hebdomadários e prefiro conservar na memória minhas especulaçóes a partilhar com aqueles cuja frivolidade e petulância não aceitam senão o que é jocoso e risível. Donde, não sejas contrário às obscuridades da brevidade, as quais são as fiéis custódias da doutrina, pois têm a vantagem de dialogar somente com aqueles que são dignos. Assim como se faz em Matemática e também em outras disciplinas, preestabeleci termos e regras pelas quais desenvolverei tudo o que segue.

Uma concepção comum é um enunciado que todos aceitam logo que é declarada. Ora, isso acontece de dois modos: aquele modo de enunciar que é táo universal que pertence a todos os homens, como quando propóes que se de dois iguais retiras grandezas iguais, o que resta é também igual; e quem entende isso não o pode negar. Outro é aquele enunciado que somente os doutos entendem, mas que derivam igualmente da mesma classe de concepções comuns, como a que diz que o incorpóreo não pode ocupar espaço e assim por diante. Estas são compreensíveis somente aos doutos e não ao vulgo.

I. Distintos são o ser [esse] e aquilo que é [id quod est]; de fato, o ser mesmo ainda não é, mas aquilo que é, tendo recebido a forma de ser [essendi forma], é e subsiste.

II. Aquilo que é pode participar de algo, mas o próprio ser não participa de nada. A participação dá-se quando algo já é, mas algo é somente quando recebeu o ser.

III. Aquilo que é pode ter algo além daquilo que ele é; contudo, o ser não tem nada mais além de si mesmo. 
IV. Há uma distinção entre simplesmente ser algo e ser algo naquilo que é. Aquele é o acidente; este, a substância.

V. Tudo aquilo que é participa daquilo que é ser para poder ser; e, para ser algo, participa também de outro. Daí que aquilo que é participa daquilo que é ser para poder ser; e é para participar em alguma outra coisa.

VI. Toda coisa simples possui em unidade o seu ser e aquilo que é; em todo composto, uma coisa é o ser e outra, o próprio é.

VII. Toda diversidade é discorde; a semelhança, porém, é apetecível. Ora, aquilo que apetece algo se mostra a si mesmo naturalmente semelhante àquilo a que apetece.

Essas premissas são, pois, suficientes; um intérprete solerte adaptará cada uma à sua argumentação.

Questão

A questão é, pois, a seguinte: são boas as coisas que são. Com efeito, segundo a sentença comum dos doutos, tudo aquilo que é tende ao bem, ou seja, tudo tende a seu semelhante; portanto, as coisas que tendem para o bem são elas mesmas boas. Mas o que importa investigar é de que modo as coisas são boas: se por participação ou por essência [substantia]. Se for por participaçáo, elas não sáo, de modo algum, boas por si mesmas. De fato, o que é branco por participação não é por si mesmo branco naquilo mesmo que ele é; o mesmo vale para outras qualidades. Se, pois, as coisas são boas por participaçáo, de modo algum são boas por si mesmas e não tendem, pois, ao bem. Concede-se-lhes, contudo, o bem. Então, elas não são boas por participação mas por essência [substantia].

Porém, as coisas cujas essências [substantia] são boas, dizem-se tais enquanto são. Ora, aquilo que elas são provém do que é ser. Com efeito, o ser das mesmas é bom. Mas, se o ser é bom, as coisas que são são boas enquanto são e o seu ser é o mesmo que o ser do bem. São, em consequência, bens substanciais, pois não participam da bondade. E se o ser mesmo nelas é bom, não há dúvida de que, porque são bens substanciais, elas são semelhantes ao primeiro bem, e, por isso, serão esse bem mesmo. Com efeito, com exceção 
dele mesmo, nada lhe é semelhante, o que faz com que todas as coisas que existem sejam Deus, o que é nefasto dizer. Não são, pois, bens substanciais e daí que o ser nelas não é bom. Não são, pois, boas enquanto são. E também não participam da bondade, nem tendem ao bem. Logo, não são de modo algum boas.

Solução

Pode-se aplicar a essa questão a solução que se segue. Numerosas são as coisas que, não sendo separadas em ato, são, contudo, separáveis pelo espírito e pelo pensamento. Assim, ninguém separa em ato um triângulo, ou as outras figuras geométricas, de sua matéria subjacente, porém cada qual considera o triângulo e o conjunto de suas propriedades, separando-o pela mente e privando-o da matéria. Afastemos do espírito por um momento a presença do primeiro bem, cuja existência é reconhecida seja por doutos, seja por ignorantes, assim como pelas religióes dos bárbaros. Removido então momentaneamente o primeiro bem, admitamos que todas as coisas que são são boas, e investiguemos de que modo poderiam ser boas se náo procedessem do primeiro bem. Intuise aí que, nelas, uma coisa é serem boas e outra, que sejam. Suponhamos ainda que uma mesma substância seja branca, pesada, redonda. Aí teríamos entáo que aquela mesma substância seria distinta de sua redondez, de sua cor e de sua bondade; de fato, se cada coisa dessas fosse o mesmo que a substância, o peso seria o mesmo que a cor e ao bem, e o bem seria o mesmo que o peso, o que repugna à natureza. Por conseguinte, uma coisa seria o ser nessas coisas e outra, o ser algo; e, então, seriam boas, mas não teriam o ser mesmo bom.

Portanto, se de algum modo elas fossem boas sem o bem, então não se identificariam com os bens, mas, para elas, uma coisa seria o ser e outra, o serem boas. Porém, se, de um modo absoluto, elas não fossem nada além de boas, e não fossem pesadas, nem coloridas, nem extensas por dimensóes do espaço, e não tivessem outra qualidade senão a de serem boas, então, manifestamente elas não seriam coisas e, sim, princípios. Por isso, antes, elas não seriam e somente o princípio seria, pois somente um único é assim: bom e nada mais. Contudo, como não são simples, de todo não poderiam ser, se o único 
que é bom não tivesse querido que fossem. De modo que, como o ser delas provém da vontade do bem, elas são chamadas boas. Com efeito, o primeiro bem, porque é, é bom naquilo que é. E o bem segundo também é bom, na medida em que promana daquele que é bom por si. Porém, o ser mesmo de todas as coisas procede igualmente daquele que é o próprio bem, e é de tal modo bom que é corretamente chamado de bom naquilo que é. Portanto, o ser mesmo das coisas é bom; com efeito, o bem nele está.

Pelo que se resolve a questão. Embora as coisas sejam boas naquilo que são, não são, contudo, semelhantes ao primeiro bem, pois, qualquer que seja o seu modo, o ser mesmo das coisas não é bom. Porém, como o ser das coisas não pode ser se não provier do primeiro ser, isto é, do bem, por tal motivo, o ser mesmo das coisas é bom sem ter semelhança àquilo pelo qual é. Pois, aquilo que de algum modo é bom é naquilo que é, e não é nada além de bom. Este, porém, se não recebesse seu ser daquele, talvez pudesse ser bom, mas não seria bom naquilo que é. Talvez participasse efetivamente do bem, porém não teria o ser bom, porquanto náo teria o próprio ser do bem. Uma vez, pois, que subtraíssemos das coisas por meio da mente e do pensamento o primeiro bem, as coisas poderiam continuar boas, mas não seriam boas naquilo que são; e em ato não poderiam existir a não ser que aquele que é o verdadeiro bem as produzisse. Por isso, o ser delas é bom sem que aquilo que proveio do bem substancial seja semelhante a ele. Se, pois, não tivessem promanado dele, mesmo que fossem boas, não poderiam ser boas naquilo que são, e estariam fora do bem sem provir do bem, já que o próprio bem primeiro é ao mesmo tempo o próprio ser e o próprio bem e o próprio ser bom.

Não aconteceria, pois, que as coisas brancas fossem brancas naquilo que são porque decorreu da vontade de Deus que fossem brancas? Absolutamente. Uma coisa é ser e outra, ser branca. E isto pela seguinte razão: aquele que fez as coisas é bom, mas de modo algum branco. Pois, pela vontade do bem, as coisas foram feitas boas naquilo que são, mas a propriedade de ser branco naquilo que é náo decorreu da vontade do não-branco. Portanto, não fluíram da vontade do branco. Destarte, porque aquele que é não-branco quis que aquelas coisas que não eram brancas fossem brancas e simplesmente brancas. Mas porque 
aquele que é bom quis que elas fossem boas, elas são boas naquilo que são. Por essa razão é necessário que todas as coisas sejam justas porque o próprio justo quis que assim fossem? Isto também não, porque ser bom refere-se à essência enquanto que o ser justo refere-ser ao agir. E como em Deus ser e agir identificam-se, nele é o mesmo ser bom e ser justo. Em nós, porque não somos simples, não é o mesmo ser que agir e, por isso, em nós não é o mesmo ser bom e ser justo; em contrapartida, o ser está em todos nós naquilo que somos. Portanto, todos nós somos bons, mas não justos. Ademais, o bem é algo geral, enquanto que o justo é algo específico, e a espécie náo atinge todas as coisas. Portanto, algumas coisas são justas, outras, outra coisa, mas todas são boas.

Referências Bibliográficas

SAVIAN FILHO, Juvenal. Metafísica do ser em Boécio. São Paulo: Loyola, 2008.

TOMÁS DE AQUINO. L'essere e la partecipazione. Commento al libro di Boezio De ebdomadibus. Trad. Carmelo Pandolfi. Bolonha: ESD, 1995. 